\title{
EXERCÍCIOS PRÁTICOS PARA O ESTUDO DE PROCESSOS GEOMORFOLÓGICOS
}

\author{
Karolina Gameiro Cota Dias ${ }^{(a)}$, Carla Maciel Salgado ${ }^{(b)}$ \\ (a) Discente do Departamento de Geografia, Universidade Federal Fluminense, karolina_dias@id.uff.br \\ (b) Docente do Departamento de Geografia, Universidade Federal Fluminense, carlasalgado@id.uff.br
}

\section{Eixo: GEOGRAFIA FÍSICA E DESASTRES NATURAIS}

\begin{abstract}
Resumo
A Geomorfologia constitui uma das principais disciplinas dentro do curso de Geografia, e possui como propósito o estudo do relevo em diferentes escalas e processos de formação. Durante a disciplina de Geomorfologia Continental, inserida no Curso de Geografia da Universidade Federal Fluminense, foram estudados os processos geomorfológicos decorrentes de ações fluviais e pluviais e a interação entre a água e os diferentes fatores constituintes do sistema Terra. Com o intuito de aplicar o conhecimento aprendido na área de geomorfologia fluvial combinado a dados públicos, disponíveis no portal online da Agência Nacional de Águas, foi desenvolvida uma atividade prática, através do programa de monitoria em Geomorfologia para os estudantes desta disciplina refletirem sobre a dinâmica hídrica no sul do estado do Rio de Janeiro.
\end{abstract}

Palavras chave: Geomorfologia, precipitação, ocupação urbana, Rio de Janeiro.

\section{Introdução}

Por ser uma ciência de grande abrangência, a Geomorfologia é dividida nas disciplinas Geomorfologia Geral, Geomorfologia Continental, e Geomorfologia Costeira na grade curricular do curso de Bacharelado em Geografia da Universidade Federal Fluminense (UFF), de forma que possa ser melhor trabalhada com suas subdivisões durante a formação do estudante. O projeto de monitoria destas disciplinas possui como principal objetivo o desenvolvimento de ferramentas didáticas e atividades práticas para o estudo dos processos geomorfológicos, buscando variar formas de aprendizado que sejam adequadas e incentivadoras para os profissionais em formação no curso.

Conciliando os conceitos e processos aprendidos na área de geomorfologia fluvial a dados diários de precipitação e cota de rios, disponíveis publicamente no portal online da Agência Nacional de Águas, foi desenvolvida uma atividade para os alunos que cursavam a disciplina Geomorfologia Continental, no semestre acadêmico 2016.1, e o presente trabalho possui como objetivo apresentar a produção deste exercício prático. Considera-se que as atividades práticas de gabinete, além de trabalhos de campo e de laboratório, são essenciais para o aluno fixar conteúdo assim como se aproximar de atividades profissionais exercidas pelo geógrafo. 


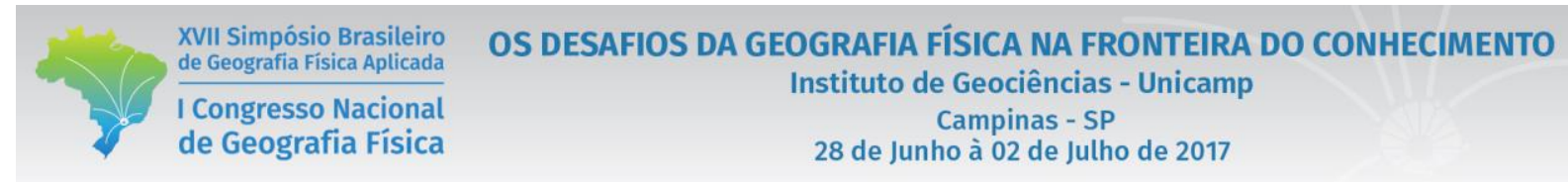

A área escolhida para estudo compreende os municípios de Angra dos Reis e Paraty, no sul do Estado do Rio de Janeiro. Estes municípios possuem fontes de água potável um pouco dispersas pelo seu território, sendo que em algumas localidades há déficit hídrico devido à demanda de um número crescente de habitantes em relação à vazão outorgável (FRANCISCO e OLIVEIRA, 2009). Por outro lado, Salgado et al. (2007) verificaram a ocorrência de inundações relacionadas à precipitação concentrada em horas ou dias, especialmente nos meses de primavera e verão.

\section{Dados e metodologia}

Para o desenvolvimento da atividade foram acessadas séries históricas com dados diários referentes às cotas dos rios Mambucaba e Perequê-Açu, nas cidades de Angra dos Reis e Paraty, respectivamente, e à precipitação nestes municípios, através do Software Hidro 1.2, disponível gratuitamente no site da Agência Nacional de Águas.

Estes dois municípios foram selecionados como área de estudo por estarem situados numa região que apresenta frequentemente altos picos de pluviosidade nos meses de verão, principalmente entre janeiro e março, e pelo fato de ambas as bacias hidrográficas possuírem extensão favorável à análise do tempo de resposta entre precipitação e aumento da cota, como é possível observar na Figura 1.

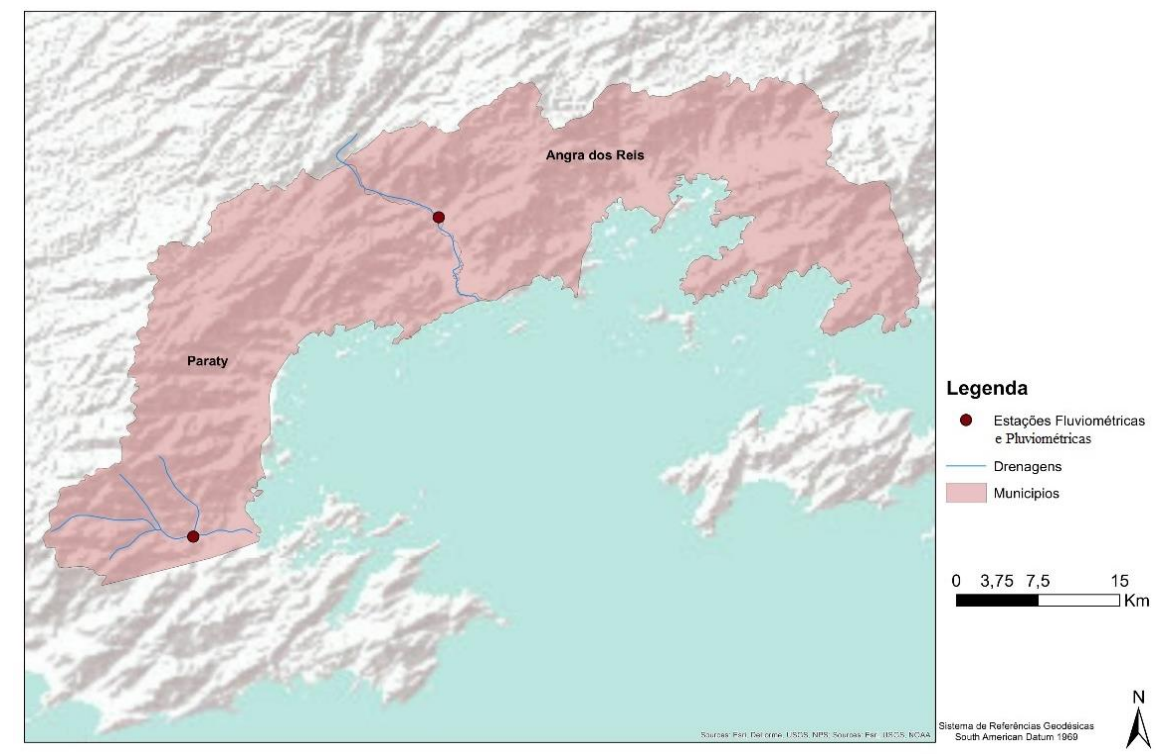

Figura 1 - Localização das estações pluviométricas e fluviométricas e dos rios Mambucaba, em Angra dos Reis, e Perequê-Açu, em Paraty. Fonte: Elaborada pela autora.

Com os dados pluviométricos e fluviométricos disponíveis, foram selecionados os anos das respectivas séries históricas em que havia a maior sequência ininterrupta de dados. Os anos em que faltavam registros de dias ou até mesmo semanas seguidas, embora poucos, foram descartados. 


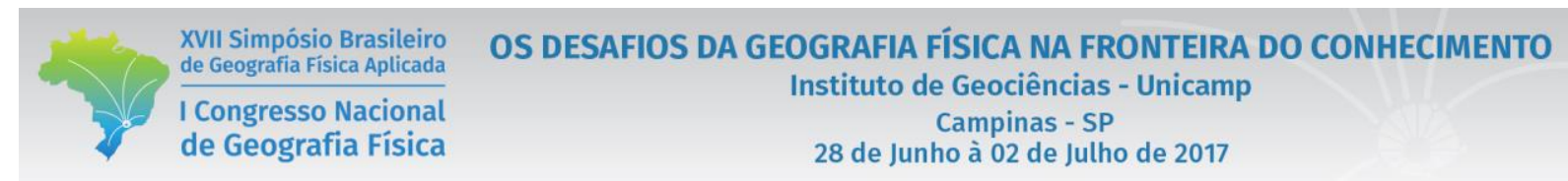

Posteriormente, foram selecionadas cerca de quatorze opções diferentes de anos para cada um dos dois municípios escolhidos, gerando um total de vinte e oito combinações de município e ano que os alunos puderam escolher para analisar individualmente ou em dupla. Os dados foram primeiramente selecionados no ambiente do software Hidro 1.2, exposto na Figura 2, e posteriormente exportados de forma a serem trabalhados em software de planilha eletrônica, com vistas a facilitar a confecção de tabelas e gráficos.

A atividade propunha para cada aluno ou dupla a confecção de três gráficos a partir do ano e município que estes escolheram: o primeiro gráfico deveria conter os dados mensais do ano selecionado, de forma que os estudantes pudessem acompanhar a dinâmica hídrica anual na região; o segundo gráfico seria produzido com os dados diários de precipitação e cota referentes ao mês de janeiro, devido à média de alta pluviosidade; o terceiro, com os dados diários do mês de agosto, devido à média de baixa pluviosidade.

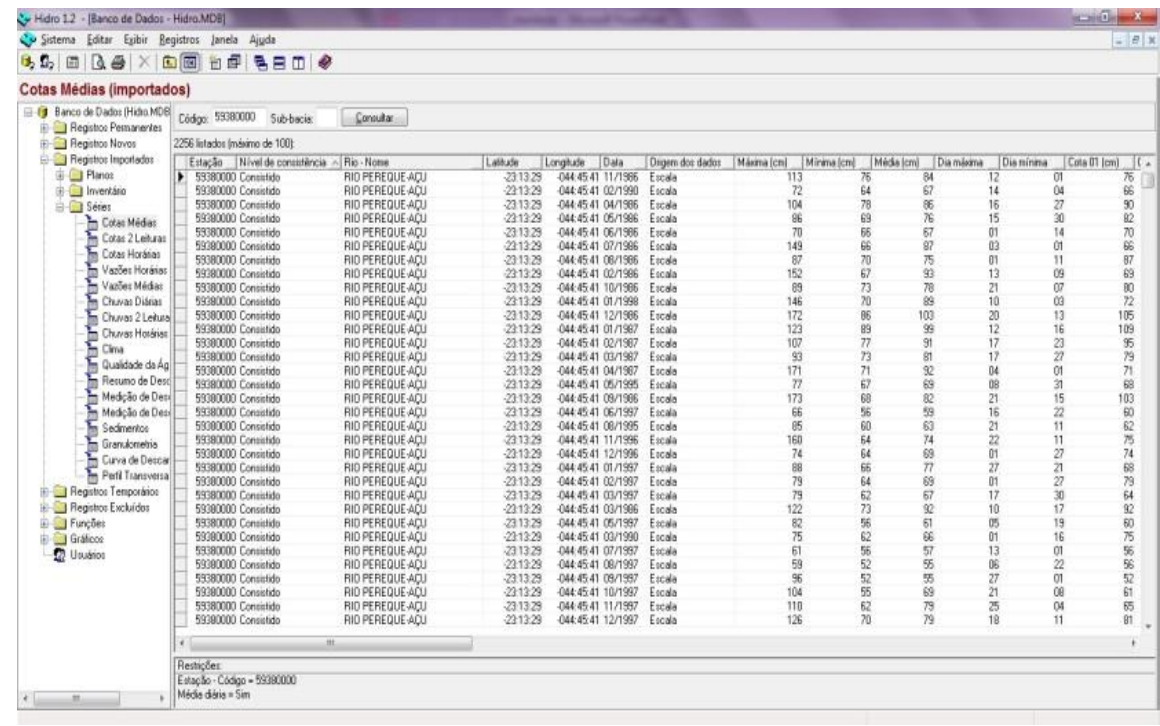

Figura 2 - Ambiente do software Hidro 1.2. Fonte: Elaborada pela autora.

Os alunos foram orientados em sala de aula e por meio de e-mail quanto ao desenvolvimento dos gráficos através de informações como:

- Os dados referentes à precipitação deveriam ser representados graficamente por colunas, e os dados referentes às cotas por linhas, e por esta razão o gráfico deveria apresentar dois eixos y;

- Os dados referentes à precipitação seriam sempre acumulados, desta forma, os dados de precipitação de determinado mês corresponderiam à soma do valor de todas as chuvas diárias desse mês, ao passo que os dados anuais de precipitação corresponderiam à soma dos dados de todos os meses de determinado ano por esta razão, o Resultado Anual, considerando a dinâmica climática na região, provavelmente seria um 


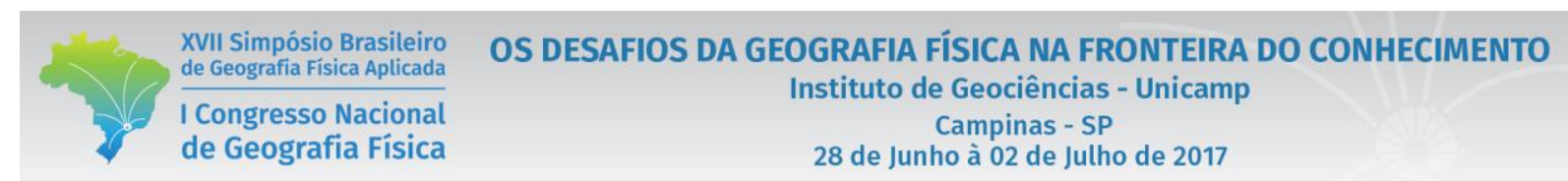

número com 4 algarismos e este seria descrito conforme o exemplo: Resultado Anual de 2357,3 mm; referente ao ano de 19xx, município 1234;

- Os dados referentes à Cota dos rios seriam sempre médias, sendo assim, os dados de cota mensal corresponderiam à média das cotas diárias de determinado mês; a cota anual corresponderia à média dos dados mensais, por esta razão, considerando a dinâmica hídrica da região, provavelmente a Média Anual seria um número com 2 ou 3 algarismos, e seria descrita conforme o exemplo: Média Anual de $118 \mathrm{~cm}$; referente ao ano 19xx, município 4321. Seguindo estas orientações os gráficos ficariam parecidos com o exemplificado na Figura 3.

Dados Paraty - 1995

\begin{tabular}{|c|c|c|}
\hline Meses & Precipitação $(\mathrm{mm})$ & Cota $(\mathrm{cm})$ \\
\hline janeiro-95 & 202,1999969 & 79 \\
\hline fevereiro-95 & 346,2000122 & 95 \\
\hline março-95 & 170,3999939 & 81 \\
\hline abril-95 & 74,59999847 & 73 \\
\hline maio-95 & 111,4000015 & 69 \\
\hline junho-95 & 63,20000076 & 64 \\
\hline julho-95 & 78,19999695 & 66 \\
\hline agosto-95 & 97,19999695 & 63 \\
\hline setembro-95 & 174,8000031 & 69 \\
\hline outubro-95 & 350,2000122 & 78 \\
\hline novembro-95 & 237,3999939 & 88 \\
\hline dezembro-95 & 139,8000031 & 77 \\
\hline
\end{tabular}

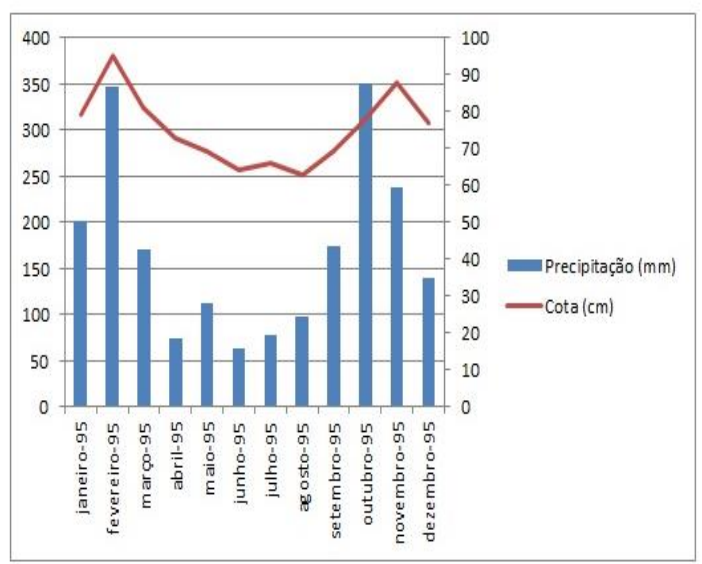

Figura 3 - Gráfico representativo dos dados pluviométricos e fluviométricos de Paraty em 1995. Fonte: Elaborada pela autora.

\section{Resultados}

O principal objetivo da atividade foi atingido com os alunos descrevendo e analisando a precipitação diária nos gráficos de janeiro e agosto, e a precipitação mensal no gráfico anual, enquanto relacionavam os períodos de maior chuva ao aumento da cota dos rios e vice-versa. Também foi proposto que os estudantes analisassem períodos de maiores e menores índices de precipitação, com o intuito de que os mesmos refletissem sobre a possibilidade de inundação nos municípios selecionados e a disponibilidade hídrica em momentos de estiagem.

Com os resultados obtidos pelos alunos, foi estimulado um debate em sala de aula sobre a questão hídrica. Neste contexto, foi discutido o papel do geógrafo e dos estudos de séries históricas para analisar a variabilidade temporal e espacial de dados de precipitação e vazão. 


\section{Conclusões}

A atividade proposta na disciplina de Geomorfologia Continental, da Universidade Federal Fluminense, de análise de dados de precipitação e de cota de rios teve estreita relação com a situação hídrica vivenciada recentemente (especialmente entre 2014 e 2015) na região Sudeste do Brasil. Esta situação aguçou o interesse do aluno no levantamento, tratamento e análise de dados primários, disponibilizados gratuitamente pela Agência Nacional de Águas. Tais dados compõem séries históricas que evidenciam variabilidades temporais e espaciais, muitas vezes ignoradas pelos gestores públicos, mas que fornecem informações fundamentais para as ações de planejamento ambiental e territorial, onde o geógrafo pode e deve atuar.

\section{Bibliografia:}

ANA - Agência Nacional de Águas, Dados Hidrológicos, Séries Históricas. Disponível em: http://hidroweb.ana.gov.br. Acesso em março, 2016.

FRANCISCO, C. N.; OLIVEIRA, C. A. V. Sustentabilidade hídrica da Região Hidrográfica da Baía da Ilha Grande, RJ. In: XIV Simpósio Brasileiro de Sensoriamento Remoto, 2009, Natal. Anais..., 2009. p. 4707-4714.

SALGADO, C.M., PEIXOTO, M.N.O. \& MOURA, J.R.S. 2007. Caracterização espaço-temporal da chuva como subsídio à análise de episódios de enchentes no município de Angra dos Reis, RJ. Geosul 22:7-26. 